\title{
ANATOMIA DA MADEIRA DE TRÊS APOCINÁCEAS DA FLORESTA ESTACIONAL DE MISSIONES, ARGENTINA
}

Graciela Ines Bolzon de Muñiz

Departamento de Eng. e Tec. Rurais - Setor de Ciências Agrárias

UFPR - Curitiba, PR

José Newton Cardoso Marchiori

Departamento de Ciências Florestais - CCR

UFSM - Santa Maria, RS

\section{RESUMO}

São descritas as madeiras de Aspidosperma australe Müll. Arg., Aspidosperma polyneuron Müll. Arg. e Rauwolfia sellowii Müll. Arg., com base em amostras coletadas na província de Missiones, Argentina. As três espécies assemelham-se quanto aos caracteres anatômicos mais importantes referidos na literatura para a família Apocynaceae. Aspidosperma australe distingue-se por ter raios homogêneos, em sua maioria unisseriados. Aspidosperma polyneuron apresenta raios predominantemente bisseriados e vasos com tilos esclerosados. Em Rauwolfia sellowii ocorrem raios mais largos e não se observam tilos em vasos.

PALAVRAS-CHAVE:Apocináceas, Aspidosperma polyneuron, Aspidosperma australe, Rauwolfia sellowii, Anatomia da madeira. 


\section{SUMMARY}

The wood anatomy of Aspidosperma australe Müll. Arg., Aspidosperma polyneuron Müll. Arg. and Rauwolfia sellowii Müll. Arg. are described, based on samples collected in the province of Misiones, Argentina. The three species showed the most important anatomic features, cited in the literature for Apocynaceae. Aspidosperma australe is identified by its homogeneous and predominantly uniseriate rays. Aspidosperma polyneuron has mostly biseriate rays and sclerotic tyloses in vessel members. Rauwolfia sellowii shows larger rays and no tyloses in its vessel members.

KEYWORDS: Apocynaceae, Aspidosperma polyneuron, Aspidosperma australe, Rauwolfia sellowii Wood Anatomy.

\section{INTRODUÇÃO}

A família Apocynaceae compreende cerca de 175 gêneros e 1500 espécies de ervas perenes, arbustos, trepadeiras e árvores pequenas a grandes, que habitam principalmente as regiões tropicais do mundo (RECORD \& HESS, 1949).

$\mathrm{Na}$ chamada "Selva Misionera" (TORTORELLI, 1956), que constitui a extensão em território argentino da Floresta Estacional Decidual (LEITE, 1994) da bacia dos rios Paraná e Uruguai, esta família botânica encontra-se representada por diversas trepadeiras, pertencentes aos gêneros Condylocarpon, Forsteronia e Peltastes, por duas espécies arbóreas de reduzido interesse madeireiro (gênero Peschiera) e três essências florestais valiosas: Aspidosperma australe, Aspidosperma polyneuron e Rauwolfia sellowii. Destas, apenas Aspidosperma australe e Rauwolfia sellowii são também nativas no Rio Grande do Sul (REITZ et al., 1983) e somente a primeira foi assinalada no levantamento florístico do Parque Estadual do Turvo (BRACK et al., 1985). 
Aspidosperma australe Müll. Arg. é árvore semidecidual de até $20 \mathrm{~m}$ de altura, tendo tronco de até $60 \mathrm{~cm}$ de diâmetro, com pequenas raízes tabulares nos indivíduos de maior porte e uma espessa casca fissurada, que exsuda abundante látex quando ferida. Conhecida em Misiones por "guatambú amarillo" ou "guatambú sayú" (MARZOCCA, 1952), recebe no Brasil os nomes de guatambu, peroba-amarela, guatambu-amarelo, guamixinga, pequiá ou pitiá (REITZ et al., 1978). Espécie heliófila e seletiva higrófila, é considerada muito agressiva em formações florestais secundárias (MARKGRAF, 1968); fornece madeira pesada, dura, com alburno esbranquiçado e cerne amarelo, amplamente indicada para a construção civil, tornearia, formas de sapatos, cabos de ferramentas e chapas (REITZ et al., 1983).

Aspidosperma polyneuron Müll. Arg., a famosa peroba ou peroba-rosa (INOUE et al., 1984) da bacia do Paraná, é conhecida por "palo rosa" ou "ibira romí" na Argentina (TORTORELLI, 1956). Originário da floresta primária densa, prefere solos férteis e profundos, formando comunidades geralmente isoladas, associadas ao palmito (Euterpe edulis). Sua madeira é moderadamente pesada, dura, compacta, de superfície opaca e áspera, fácil de rachar e muito durável, desde que não em contato com solo ou umidade (CARVALHO, 1994).

Rauwolfia sellowii Müll. Arg. é árvore semidecídua, heliófila e seletiva higrófila, que alcança $25 \mathrm{~m}$ de altura e $50 \mathrm{~cm}$ de diâmetro no tronco. Conhecida no Brasil como casca-d'anta ou jasmim-grado, recebe em Missiones os nomes de "quina" e "quina del monte" (MUÑIZ, 1993). Fornece madeira leve, macia, pouco compacta, fácil de trabalhar e de baixa durabilidade natural, indicada para forros, caixotaria e confecção de brinquedos ou artefatos leves (LORENZI, 1992).

A estrutura anatômica das Apocináceas reúne poros usualmente pequenos, exclusivamente solitários ou com numerosos múltiplos, placas de perfuração simples, pontoações intervasculares ornamentadas e muito pequenas ou diminutas; elementos de vaso 
moderadamente curtos até moderadamente longos e parênquima geralmente apotraqueal (METCALFE \& CHALK, 1972; RECORD \& HESS, 1949). As fibras, de muito curtas a moderadamente longas, podem ter pontoações simples ou nitidamente areoladas e serem septadas ou desprovidas de septos. Os raios, geralmente heterogêneos e com diversas fileiras marginais de células quadradas e eretas, possuem até 3 células de largura e menos de $1 \mathrm{~mm}$ de altura, nas espécies desprovidas de septos em fibras, ou de 3 a 5 células de largura e mais de $1 \mathrm{~mm}$ de altura, nas espécies com fibras septadas (RECORD \& HESS, 1949). Laticíferos são reportados para 17 gêneros, incluindo Hancornia, Nerium e Peschiera (METCALFE \& CHALK, 1972).

Para a madeira de Aspidosperma australe, TORTORELLI (1956) refere anéis de crescimento pouco demarcados, porosidade difusa e poros predominantemente solitários, elípticos ou arredondados, com freqüência de 80 a 100 por $\mathrm{mm}^{2}$ e diâmetro tangencial de $40-50-70 \mu \mathrm{m}$. São também descritos elementos vasculares curtos a medianos (280 - 485 $700 \mu \mathrm{m}$ ), parênquima apotraqueal difuso e fibras libriformes de 13 a $15 \mu \mathrm{m}$ de diâmetro, com 740 - 970 - $1210 \mu \mathrm{m}$ de comprimento. Os raios, homogêneos, de células procumbentes e com freqüência de 8 a 10 por mm, são quase sempre unisseriados, medindo de 40 - 120 - $400 \mu \mathrm{m}$ de altura. Em descrição macroscópica, TUSET \& DURAN (1970) registram a presença de poros visíveis apenas sob lupa, desprovidos de conteúdos e em porosidade difusa, de parênquima axial invisível, mesmo sob lupa e de raios lenhosos finos, numerosos e em disposição irregular.

Para a madeira de Aspidosperma polyneuron, TORTORELLI (1956) descreve anéis de crescimento pouco demarcados, posidade difusa, elementos vasculares curtos a médios (150 - 430 - $500 \mu \mathrm{m})$, placas de perfuração simples e pontoações intervasculares pequenas. Os poros, solitários e elípticos ou arredondados, são referidos como muito numerosos (45 - 65/mm2) e de diâmetro pequeno a médio $(40-80-120 \mu \mathrm{m})$. O autor refere ainda a presença de fibras libriformes septadas, com paredes espessas e 700 - 1000 - $1250 \mu \mathrm{m}$ de comprimento, bem como raios 70 Rev. Ciência e Natura, Santa Maria, 20: $67-83$, 1998. 
numerosos $\left(8-11 / \mathrm{mm}^{2}\right)$, geralmente bisseriados, relativamente baixos $(70$ $270-500 \mu \mathrm{m}$ ) e parênquima difuso ou difuso-em-agregados.

Sobre Rauwolfia sellowii não foram encontradas referências à estrutura anatômica de sua madeira. Para certas espécies do gênero, entretanto, METCALFE \& CHALK (1972) referem a ocorrência de poros exclusivamente solitários, com 100 a $200 \mu \mathrm{m}$ de diâmetro e de raios com até 4 ou 6 células de largura. Em Rauwolfia duckei Markgraf foram observadas algumas curtas placas de perfuração escalariforme (RECORD \& HESS, 1949).

O presente trabalho visa o estudo descritivo destas três importantes espécies de madeira e sua identificação, com base na estrutura anatômica.

\section{MATERIAIS E MÉTODOS}

O material estudado consiste de 3 amostras de madeira para cada espécie, provenientes de uma floresta da "Universidad Nacional de Misiones", localizada nos municípios "El Soberbio" e "Colonia Aristóbulo del Valle", no departamento de "Guaraní", Argentina.

Os corpos de prova utilizados para o preparo das lâminas anatômicas foram obtidos da parte mais externa de discos do tronco, extraídos a 1,30 m do solo. O material lenhoso e respectivas exsicatas de material botânico foram incorporados às coleções do Laboratório de Dendrologia, da "Facultad de Ciencias Forestales" da mesma universidade. Os trabalhos de microtécnica foram realizados no Laboratório de Anatomia da Madeira, da Universidade Federal do Paraná

Os corpos de prova foram orientados para a obtenção de cortes nos planos transversal, longitudinal radial e longitudinal tangencial. Após o amolecimento por fervura em água, os corpos de prova foram seccionados em micrótomo de deslizamento, modelo Spencer AO $n^{\circ} \mathbf{8 6 0}$, com espessura variável entre 14 e $24 \mu \mathrm{m}$. Para o tingimento dos cortes 
anatômicos utilizou-se o método de tripla coloração, com vermelho-deacridina, crisoidina e azul-de-astra (DUJARDIN, 1964). Os cortes foram a seguir desidratados em série alcoólica ascendente, diafanizados com xilol e montados em lâminas permanentes, com "Entellan".

Para a maceração dos tecidos seguiu-se o método de Jeffrey (FREUND, 1970), usando-se coloração com safranina e o mesmo meio de montagem anteriomente referido.

Os dados quantitativos dos caracteres anatômicos foram processados diretamente no aparelho analisador de imagens "Videoplan", acoplado a um computador, obtendo-se desta forma os respectivos valores médios, máximos, mínimos e desvio padrão, com o uso de programas aplicativos.

Para as descrições microscópicos e mensurações de elementos celulares individuais seguiram-se as normas ABNT, com as alterações introduzidas por MUÑIZ (1986).

Para as fotomicrografias usou-se filme Kodak-Panatomic $\mathrm{X}$, ASA 32 e ampliações em papel fotográfico Kodabromid F-3 brilhante.

\section{RESULTADOS}

\section{Aspidosperma australe Müll. Arg.}

Caracteres gerais: Madeira de cerne e alburno indistintos, amarelo-clara, que adquire tom amarelo-rosado ou pardo-claro-amarelado após prolongada exposição. Moderadamente pesada $\left(0,70\right.$ a $\left.0,78 \mathrm{~g} / \mathrm{cm}^{3}\right)$, apresenta superfície lisa e pouco lustrosa, textura fina homogênea e grã direita.

Anéis de crescimento: Pouco demarcados e apenas distinguíveis pelo parênquima axial marginal, em faixa muito estreita (Figura $1 \mathrm{~A})$. 
Vasos: Em porosidade difusa, com poros predominantemente solitários (95\%), raramente geminados ou racemiformes (até 3 poros) e de seção elíptica ou arredondada (Figura 1 A,B); muito numerosos (50 $80 / \mathrm{mm}^{2} ; \mathrm{s}=4,12$ ), variam de $40-65-76 \mu \mathrm{m}$ de diâmetro $(\mathrm{s}=23,12)$. Linhas vasculares retilíneas a levemente sinuosas. Elementos vasculares de 280 505 : $700 \mu \mathrm{m}(\mathrm{s}=32,4)$ de comprimento e com longos apêndices (até 200 $\mu \mathrm{m})$, em uma ou ambas extremidades. Placas de perfuração exclusivamente simples e levemente oblíquas. Pontoações intervasculares alternas, pequenas $(2,5-4-5,5 \mu \mathrm{m} ; \mathrm{s}=2,11)$, de forma circular a oblonga e com abertura lenticular inclusa. Pontoações raio-vasculares e parênquimovasculares, semelhantes às intervasculares.

Parênquima axial: Predominantemente apotraqueal difuso (Figura 1.B) e difuso-em-agregados; também marginal (Figura 1 A), em finas linhas interrompidas ou em faixas de 1 a 3 células. Parênquima axial seriado, com séries de 4 a 6 células e 140 a $400 \mu \mathrm{m}(s=13,67)$ de comprimento, por cerca de 20 um de diâmetro.

Raios: Homogêneos, numerosos (8 a 10 raios $/ \mathrm{mm}$ ), não estratificados (Figura 1.D), constituídos apenas de células horizontais (Figura 1.C) e com presença de gomo-resina. Medem de $60-200-250 \mu \mathrm{m}$ ( $\mathrm{s}=$ 35,32 ) de altura, com 2 a 15 células e são predominantemente unisseriados (91\%), mais raramente bisseriados ou parcialmente bisseriados (Figura 1.D).

Fibras: Fibrotraqueídeos, freqüentemente gelatinosos, septados e com pontoações areoladas conspícuas $(4 \mu \mathrm{m})$. Apresentam paredes espessas e variam de $740-1160-1340 \mu \mathrm{m}(\mathrm{s}=168,32)$ de comprimento por 12 - 17 - $30 \mu \mathrm{m}$ de diâmetro.

\section{Aspidosperma polyneuron Müll. Arg.}

Caracteres gerais: Madeira de alburno amarelado e cerne variando do róseo-amarelado ao vermelho-rosado, uniforme ou com veios e 
manchas escuras. Figura pouco pronunciada, mas com desenho acetinado em alguns indivíduos, que confere grande valor ornamental. Textura fina e homogênea, grã direita ou revessa, com superfície lisa ao tato. Cheiro inperceptível e gosto ligeiramente amargo. Madeira dura e semi-pesada $\left(0,65-0,79 \mathrm{~g} / \mathrm{cm}^{3}\right)$, de baixa resistência ao ataque de organismos xilófagos e baixa permeabilidade às soluções preservantes, mesmo em tratamentos sob pressão.

Anéis de crescimento: Fracamente demarcados, mediante zonas fibrosas de paredes mais espessas (Figura $2 \mathrm{~A}$ ).

Vasos: Em porosidade difusa (Figura $2 \mathrm{~A}, \mathrm{~B}$ ), em sua maioria solitários (89\%), menos comumente geminados e em múltiplos racemiformes, de seção ovalada, elíptica ou arredondada (Figura 2.A), com freqüência de 45 a 80 vasos $/ \mathrm{mm}^{2}(s=4,78)$ e com diâmetro tangencial variável de $20-80-120 \mu \mathrm{m}(\mathrm{s}=29,75)$. Linhas vasculares mais ou menos retilíneas. Elementos vasculares de $150-460-500 \mu \mathrm{m}(s=36,54)$ de comprimento, com longos apêndices em uma ou em ambas extremidades e contendo tilos esclerosados (Figura 2.D). Placas de perfuração exclusivamente simples e de transversais (Figura 2.B) a levemente oblíqüas. Pontoações intervasculares alternas, minúsculas $(2,5$ - 3,5 - 5,5 $\mu \mathrm{m} ; \mathrm{s}=0,99)$, de forma circular e com abertura lenticular inclusa. As pontoações raiovasculares e parênquimo-vasculares, semelhantes em tamanho e forma às intervasculares.

Parênquima axial: Tipicamente apotraqueal difuso e difusoem agregados; do tipo seriado e com 200 a $650 \mu \mathrm{m}(\mathrm{s}=11,09)$ e 2 a 6 células de altura; células do parênquima axial formando séries cristalíferas de até 10 câmaras, com monocristais e maclas de oxalato de cálcio, abundantes no meio do tecido fibroso e contribuindo para o aumento da densidade e dureza da madeira. As células parenquimáticas também apresentam conteúdo semelhante a gomo-resina.

Raios: Com freqüência de 7 a 11 raios $/ \mathrm{mm}$, homogêneos a fracamente heterogêneos (Figura 2.C) e constituídos em sua maioria por 
células procumbentes, ocasionalmenmte com poucas células quadradas a levemente eretas nas margens. Com 1 a 3 células de largura, predominam os bisseriados (Figura 2.D), sendo raros os unisseriados. Medem de 70 - 290 - $500 \mu \mathrm{m}(\mathrm{s}=23,65)$, com até 30 células de altura. Observa-se abundante gomo-resina; cristais e maclas de oxalato de cálcio, escassas.

Fibras: De $710-1000-1250 \mu \mathrm{m}$ de comprimento ( $\mathrm{s}=$ $212,12)$, septadas, com paredes espessas (10 - $15-20 \mu \mathrm{m})$ e pontoações areoladas pequenas, embora distintas.

\section{Rauwolfia sellowii Müll. Arg.}

Caracteres gerais: Madeira de alburno amarelado e cerne variando de creme a castanho claro, de textura fina e homogênea, com grã direita ou inclinada e superfície lisa ao tato. Dura e semi-pesada, possui massa específica variável de 0,65 a $0,70 \mathrm{~g} / \mathrm{cm}^{3}$ e apresenta baixa durabilidade quando em contato com o solo.

Anéis de crescimento: Indistintos.

Vasos: Em porosidade difusa (Figura 3.A); em sua maioria solitários $(81 \%)$, menos comumente geminados e em múltiplos radiais e racemiformes de poucos vasos (Figura 3.A,B). De seção elíptica ou arredondada, ocorrem com freqüência de 18 a 50 vasos $/ \mathrm{mm}^{2}$ ( $\mathrm{s}=5,10$ ), tendo diâmetro tangencial de $62,5-95-120 \mu \mathrm{m}(\mathrm{s}=4,65)$. Linhas vasculares retilíneas a levemente sinuosas. Elementos vasculares de 110 476 - $650 \mu \mathrm{m}$ ( $s=29,09)$ de comprimento, com apêndices em uma ou em ambas extremidades. Placas de perfuração simples, transversais a levemente oblíquas. Pontoações intervasculares alternas e pequenas, variando de 2,5 a $7 \mu \mathrm{m}$ de diâmetro ( $s=0,65$ ), tendo forma circular e abertura lenticular inclusa. Pontoações raio-vasculares e parênquimovasculares, semelhantes às intervasculares. 
Parênquima axial: Em séries de 2 a 6 células, medindo de 370 a $500 \mu \mathrm{m}$ de altura e em arranjo predominantemente apotraqueal; nos padrões difuso e difuso-em-agregados, mas também paratraqueal escasso.

Raios: Heterogêneos (Figura 3.C,D), com freqüência de 2 a 6 raios por $\mathrm{mm}$ e 340 - $490-650 \mu \mathrm{m}(\mathrm{s}=45,78)$ de altura. Raios multisseriados com 2- 4 - 5 células de largura, constituídos por células procumbentes na parte central e células quadradas e eretas nas margens (Figura 3.C). Os unisseriados, constituídos principalmente por células quadradas e eretas. Células radiais com freqüentes monocristais romboédricos, prismáticos e maclas de oxalato de cálcio (Figura 3.C). Células perfuradas de raio, ocasionais; raios fusionados, freqüentes.

Fibras: Fibrotraqueídeos septados, com pequenas pontoações areaoladas mais abundantes na face radial da parede. Medem de 790 - 940 $1210 \mu \mathrm{m}$ de altura $(s=121,09)$, por 12,5 a $16 \mu \mathrm{m}(\mathrm{s}=2,30)$ de diâmetro e possuem paredes espessas.

\section{DISCUSSÃO}

Os principais caracteres anatômicos observados nas madeiras de Aspidosperma australis, Aspidosperma polyneuron e Rauwolfia sellowii correspondem ao referido na literatura, por METCALFE \& CHALK (1972) e RECORD \& HESS (1949). A ocorrência nestas espécies de poros predominantemente solitários, com placas de perfuração simples, pontoações intervasculares pequenas a diminutas e parênquima apotraqueal difuso, são amplamente observados na família Apocinaceae, de acordo com os mesmos autores.

Os valores relativos ao diâmetro de poros e fibras, bem como o comprimento de fibras e elementos vasculares, determinados no presente trabalho para Aspidosperma australe, assemelham-se bastante aos referidos por TORTORELLI (1956), para a mesma espécie. No material examinado, por outro lado, registrou-se uma menor freqüência de poros. 
O estudo de Aspidosperma polyneuron também forneceu valores bastante semelhantes ao indicado por TORTORELLI (1956) para a espécie, principalmente quanto à freqüência e diâmetro de poros, comprimento de elementos vasculares e fibras, e altura e freqüência de raios. A predominância de raios bisseriados, de fibras septadas, observadas no presente estudo, também corresponde ao descrito pelo anatomista argentino.

As escassas referências disponíveis sobre o gênero Rauwolfia fornecem poucos elementos para a análise estrutural da espécie estudada Em Rauwolfia sellowii, contudo, observou-se um diâmetro de poros menor do que o indicado por METCALFE \& CHALK (1972) para o gênero e comprovouse a ocorrência de poros em múltiplos radiais e racemiformes, apesar da predominância de solitários. Resta destacar que a ocorrência de raios com 2 a 5 células de largura coincide com o descrito pelos mesmos autores para o gênero em questão.

A análise da estrutura radial contribui decisivamente para a separação das espécies estudadas: Aspidosperma australe separa-se de Aspidosperma polyneuron e de Rauwolfia sellowii por ter raios homogêneos predominantemente unisseriados. Em Aspidosperma polyneuron, os raios são também homogêneos ou fracamente heterogêneos, mas com 1 a 3 células de largura, enquanto em Rauwolfia sellowii, são nitidamente heterogêneos e multisseriados. Aspidosperma australe distingue-se ainda pela ausência de cristais no tecido lenhoso.

A separação de Aspidosperma polyneuron e Rauwolfia sellowii pode ser facilmente realizada pelo exame dos raios e vasos. Na primeira, ocorrem raios predominantemente bisseriados e abundantes tilos esclerosados nos vasos. Em Rauwolfia sellowii, ao contrário, os raios são nitidamente mais largos (até 6 células), predominando os tetrasseriados e os vasos carecem de tilos esclerosados. 


\section{CONCLUSÕES}

O estudo anatômico da madeira das três espécies de Apocináceas da Floresta Estacional de Misiones, presentemente descritas, indicam as seguintes conclusões:

- Tanto Aspidosperma polyneuron como Aspidosperma australe e Rauwolfia sellowii reúnem os caracteres anatômicos mais importantes da família Apocynaceae, citados na literatura: poros pequenos e predominantemente solitários, placas de perfuração simples, pontoações intervasculares muito pequenas ou diminutas e parênquima apotraqueal. As mesmas espécies também se assemelham pela presença de septos nas fibras lenhosas.

- A identificação das três espécies pode ser facilmente realizada através da anatomia da madeira.

- Aspidosperma australe distingue-se pelos raios homogêneos predominantemente unisseriados e pela ausência de cristais na estrutura lenhosa.

- Aspidosperma polyneuron identifica-se pelos raios predominantemente bisseriados e vasos com tilos esclerosados.

- Rauwolfia sellowii apresenta raios mais largos, em sua maioria tetrasseriados, além de vasos desprovidos de tilos.

- Os valores numéricos obtidos para os diferentes caracteres anatômicos de Aspidosperma australe e Aspidosperma polyneuron são em geral bastante semelhantes aos referidos na literatura para as respectivas espécies. 


\section{LITERATURA CITADA}

BRACK, P., BUENO, R.M., FALKENBERG, D.B., PAIVA, M.R.C., SOBRAL, M., STEHMANN, J.R. Levantamento florístico do Parque Estadual do Turvo, Tenente Portela, Rio Grande do Sul, Brasil. Roessléria, Porto Alegre, n. 7, p. 69-94, 1985.

CARVALHO, P.E.R. Espécies Florestais Brasileiras - Recomendações Silviculturais, Potencialidades e Uso da Madeira. Colombo: EMBRAPA, Centro Nacional de Pesquisa de Florestas, 1994. 639 p.

DUJARDIN, E.P. Eine neue Holz-zellulosenfaerbung. Mikrokosmos, n. 53, p. 94, 1964.

FREUND, H. Handbuch der Mikroskopie in der Technik. Frankfurt, Umschan Verlag, $1970.379 \mathrm{p}$.

INOUE, M.T., RODERJAN, C.V., KUNIYOSHI, Y.S. Projeto Madeira do Paraná. Curitiba: Fundação de Pesquisas Florestais do Paraná, 1984. $260 \mathrm{p}$.

LEITE, P.F. As diferentes unidades fitoecológicas da região sul do Brasil - Proposta de classificação. Curitiba: Universidade Federal do Paraná, Curso de Pós-Graduação em Engenharia Florestal, 1994. Dissertação de Mestrado.

LORENZI, H. Árvores Brasileiras - Manual de Identificação e Cultivo de Plantas Arbóreas Nativas do Brasil. Nova Odessa: Editora Plantarum Ltda, 1992. $352 \mathrm{p}$.

MARKGRAF, F. Apocináceas. In: REITZ, R. (ed.). Flora llustrada Catarinense. Itajaí: Herbário Barbosa Rodrigues, 1968. 112 p.

MARZOCCA, A. Las Plantas Cultivadas en la Republica Argentina Apocinaceas. Buenos Aires: Instituto Nacional de Tecnologia Agropecuaria, 1952. v. 9, fasc. 163, p. 37 p.

METCALFE, C.R., CHALK, L. Anatomy of the Dicotyledons. Oxford: Clarendon Press, 1972. 1500 p.

MUÑIZ, G.I.B. Descrição da estrutura e ultraestrutura da madeira de cinco espécies de Prosopis da Argentina e análise da metodologia. Curitiba, Universidade Federal do Paraná, Curso de Pós-Graduação em Engenharia Florestal, 1986. 192 f. Dissertação de Mestrado. 
MUÑIZ, G.I.B. Anatomia da madeira de espécies arbóreas da Floresta Estacional Semidecidual de Misiones, Argentina. Curitiba, Universidade Federal do Paraná, Departamento de Engenharia e Tecnologia Rurais, 1993. 152 f. Tese para o concurso de Professor Titular.

RECORD, S.J., HESS, R.W. Timbers of the New World. New Haven, Yale University Press, 1949. 640 P.

REITZ, R., KLEIN, R.M., REIS, A. Projeto Madeira de Santa Catarina. Sellowia, Itajaí, n. 28-30, p. 1-320, 1978.

REITZ, R., KLEIN, R.M., REIS, A. Projeto Madeira do Rio Grande do Sul. Sellowia, Itajaí, n. 34-35, p. 1-525, 1983

TORTORELLI, L.A. Maderas y Bosques Argentinos. Buenos Aires: Editorial ACME, 1956. 910 p.

TUSET, R., DURAN, F. Descripcion y Clave Macroscopicas de Maderas Comerciales en Uruguay. Montevideo, Universidad de La Republica, Facultad de Agronomia, 1970. Bol n. 114, 63 p. 

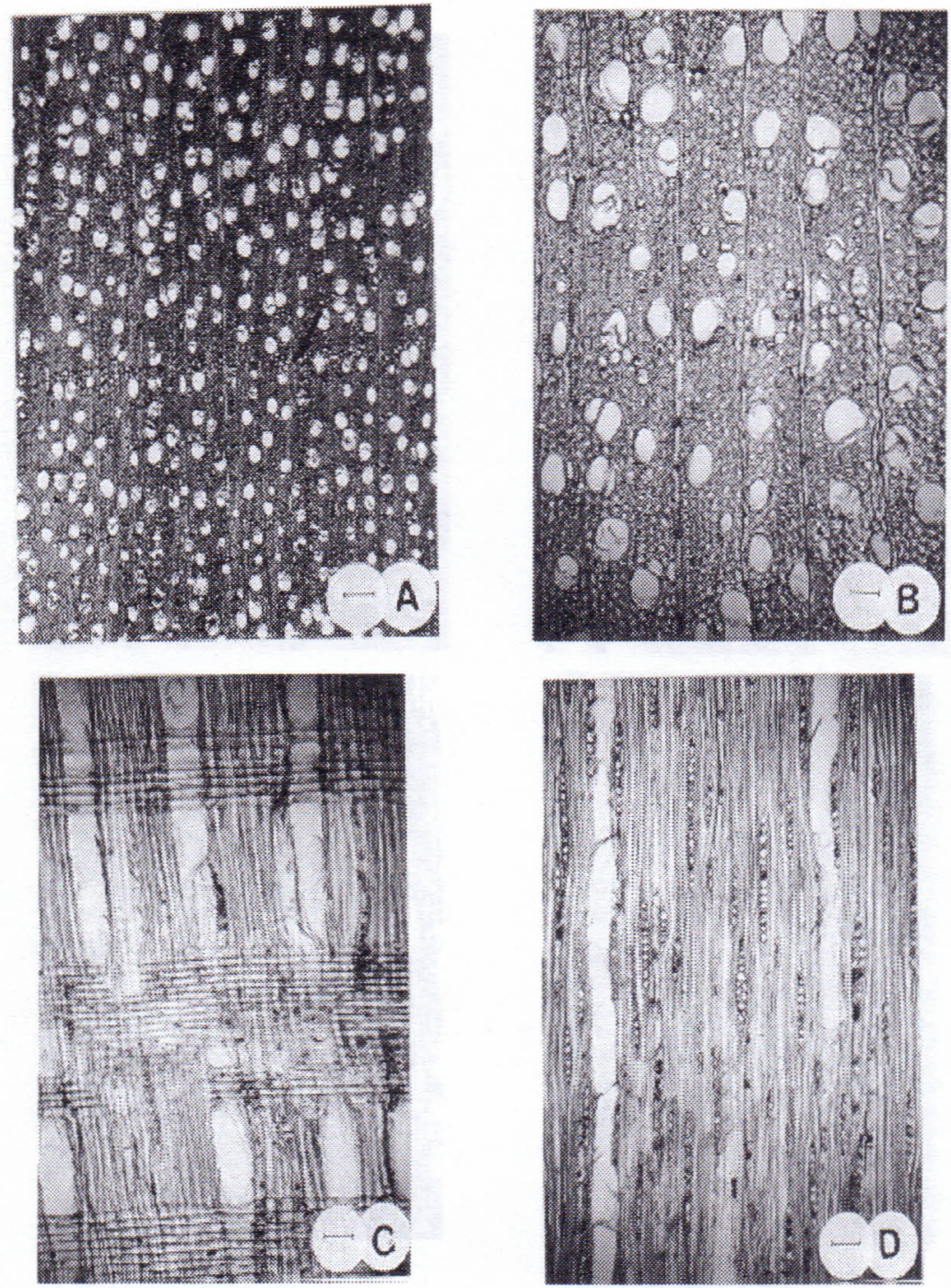

Figura 1: Aspidosperma australe Müll. Arg. A. Seção transversal da madeira, mostrando poros predominantemente solitários, abundantes e parênquima apotraqueal difuso ou difuso-em-agregados; (escala $=100 \mu \mathrm{m})$. B. Detalhe da seção transversal, salientando poros solitários e parênquima apotraqueal difuso; (escala $=40 \mu \mathrm{m})$. C. Raios de tecido homogêneo, compostos inteiramente de células horizontais, em seção; (escala $=40 \mu \mathrm{m})$. D. Raios predominantemente unisseriados, em seção longitudinal tangencial; (escala $=40 \mu \mathrm{m})$.

Rev. Ciência e Natura, Santa Maria, 20: $67-83,1998$. 

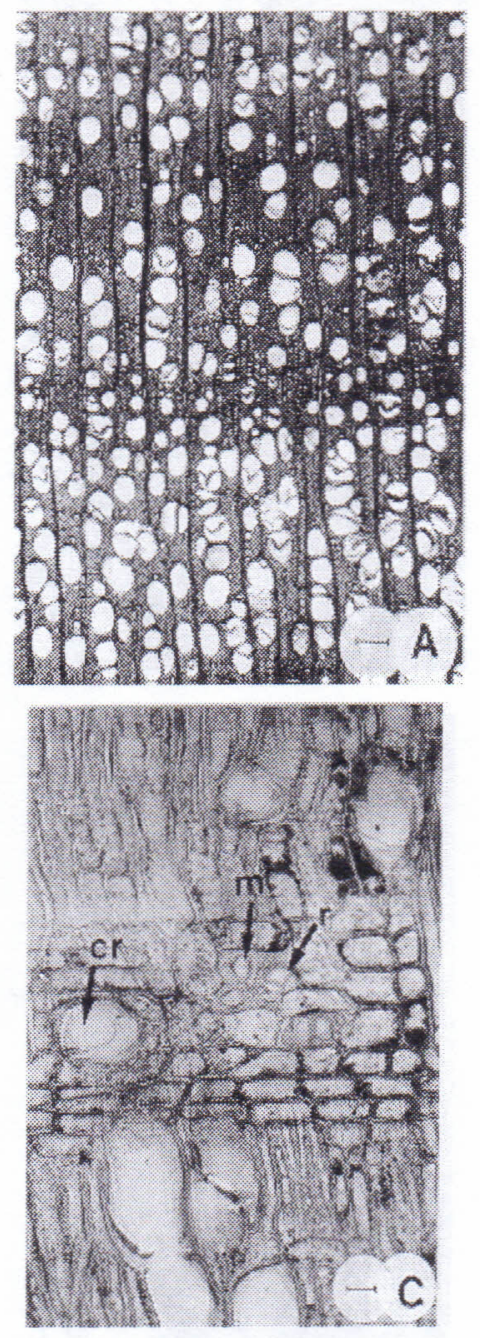
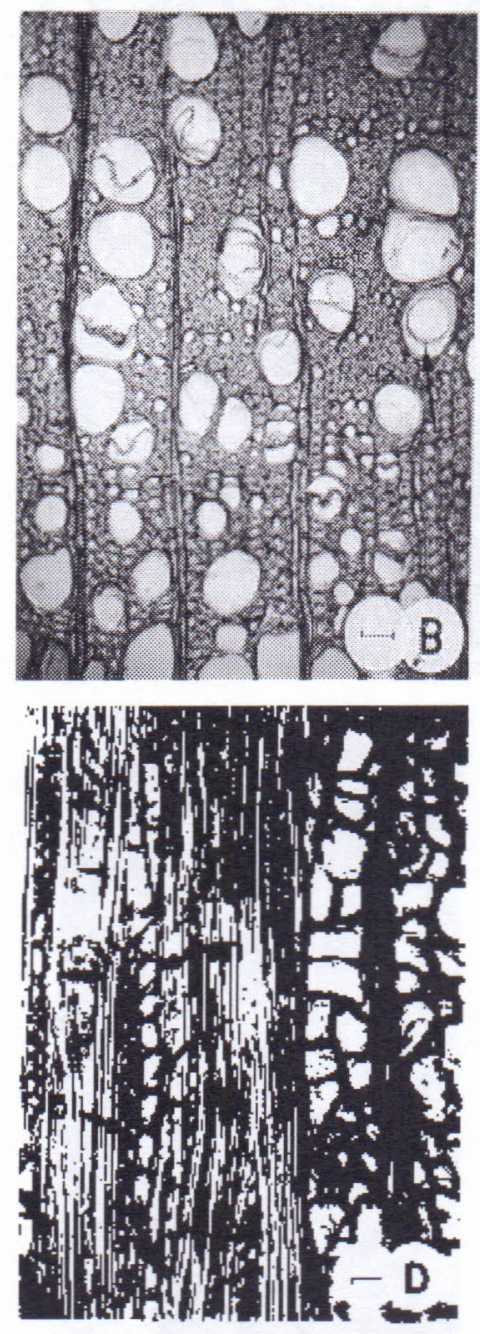

Figura 2: Aspidosperma polyneuron Müll. Arg. A. Anel de crescimento fracamente demarcado e poros geralmente solitários, em seção transversal; (escala = $100 \mu \mathrm{m})$ B. Seção transversal, destacando o parênquima apotraqueal difuso ou difuso-em-agregados e placa de perfuração simples (seta); (escala = 40 $\mu \mathrm{m})$. C. Raios fracamente heterogêneos, com células perfuradas (cr), monocristais de oxalato de cálcio romboédricos ( $r$ ) e maclas $(m)$, em seção longitudinal radial; (escala $=25 \mu \mathrm{m}$ ). D. Seção longitudinal tangencial (escala $=25 \mu \mathrm{m})$, mostrando raios bisseriados, tilos esclerosados em elementos de vaso (t) e séries cristalíferas no parênquima axial (c), com monocristais romboédricos $(r)$ e maclas $(m)$.

82 Rev. Ciência e Natura, Santa Maria, 20: 67 - 83 , 1998 

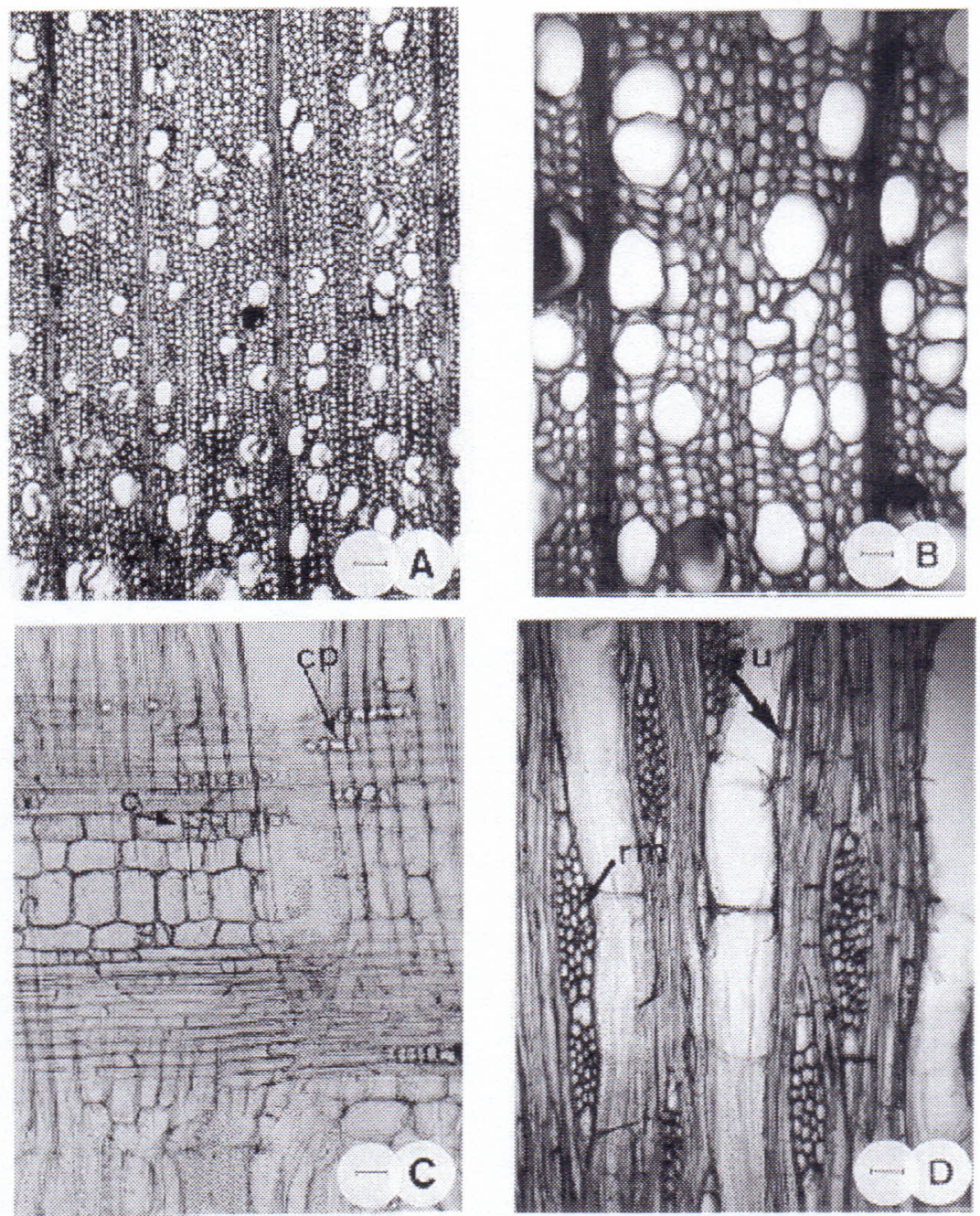

Figura 3: Rauwolfia sellowii Müll. Arg. A. Seção transversal (escala $=100 \mu \mathrm{m})$, mostrando porosidade difusa e poros solitários ou em múltiplos radiais e racemiformes de poucos vasos. B. Detalhe da seção transversal, com maior aumento (escala $=40 \mu \mathrm{m})$. C. Seção longitudinal radial (escala $=40$ $\mu \mathrm{m})$, mostrando raios heterogêneos, com monocristais romboédricos prismáticos $(\mathrm{cp})$ e maclas de oxalato de cálcio, além de elementos de vaso com pontoações intervasculares e raio-vasculares minúsculas. D. Seção tangencial (escala $=40 \mu \mathrm{m}$ ), mostrando raios multisseriados ( $\mathrm{rm}$ ) e unisseriados (ru).

Rev. Ciência e Natura, Santa Maria, 20: 67 - 83 , 1998. 
84 Rev. Ciência e Natura, Santa Maria, 20: 67 - 83, 1998. 